\title{
Peningkatan Kreativitas Usaha Melalui Pembentukan Komunitas Pemuda Kreatif Desa Guntur Macan Kecamatan Gunung Sari Kabupaten Lombok Barat
}

\author{
Muhammad Arwan Rosyadi*, Syarifuddin, Taufiq Ramdani, Anisa Puspa Rani \\ Program Studi Sosiologi Universitas Mataram, Mataram-Indonesia
}

\begin{abstract}
Kata Kunci:
Abstrak: Pada tahun 2016, sebanyak 76,17 persen (486 dari $826 \mathrm{KK}$ ) penduduk komunitas, Desa Guntur Macan Kecamatan Gunung Sari Kabupaten Lombok Barat tergolong pemuda, kreatif miskin. Jumlah tersebut diprediksi meningkat, terutama setelah terjadi gempa bumi Lombok pada medio 2018 yang menyebabkan 876 rumah $(97 \%)$ warga rusak berat. Pengangguran pun semakin bertambah. Meningkatnya jumlah pengangguran juga disebabkan bertambahnya angka putus sekolah. Perlu pembentukan komunitas pemuda kreatif yang aktif bergerak di bidang sosial dan ekonomi, guna mengatasi problematika pemuda putus sekolah dan pengangguran, sekaligus sebagai sarana penyaluran potensi sosial pemuda.

Pembentukan komunitas tersebut diawali dengan pemetaan potensi pemuda, lalu FGD (focus group discussion) yang menyertakan pemuda Desa Guntur Macan sebagai peserta utama. FGD ini berfungsi memahamkan urgensi pembentukan komunitas pemuda kreatif, sekaligus rekayasa sosial menumbuhkan minoritas kreatif sebagai unsur perubahan. Program selanjutnya: Sarasehan dan Launching Komunitas, sebagai upaya menyamakan persepsi antara pemuda dan warga desa, serta pengokohan terbentuknya komunitas pemuda kreatif. Kegiatan ini menghasilkan terbentuknya komunitas pemuda kreatif Desa Guntur Macan, yang berimbas pada kegiatan-kegiatan positif lainnya: workshop Cara Murah dan Kreatif Mengolah Botol Bekas Menjadi Hiasan Berharga, dan pelatihan Cara Kreatif Membangun Jejaring Sosial Online Tanpa Keluar Rumah.
\end{abstract}

\section{Korespondensi: arwan@unram.ac.id}

\section{PENDAHULUAN}

Angka Kemiskinan Nusa Tenggara Barat tergolong tinggi. NTB menduduki posisi ke8 dari semua provinsi di Indonesia (2018). Pada tahun 2016, jumlah penduduk miskin di NTB mencapai 823.890 jiwa atau setara 17,10 persen (14,75 persen di 2018). Penduduk miskin Kabupaten Lombok Barat mencapai 17,38 persen (15,20 persen di 2018). Berdasar data Pemerintah Desa Guntur Macan Kecamatan Gunung Sari Kabupaten Lombok Barat, di Desa Guntur Macan, 1.705 jiwa (486 Kepala Keluarga) dari 2.240 jiwa (826 Kepala Keluarga) atau 76,17 persen penduduknya tergolong miskin pada tahun 2016 (dua tahun sebelum terjadi gempa bumi Lombok 2018).

Pascagempa bumi, jumlah KK miskin dan pengangguran diprediksi meningkat tajam. Hal itu disebabkan adanya faktor makro maupun mikro ekonomi. Bupati Lombok Barat, Fauzan Khalid menyatakan bahwa kerugian akibat bencana mencapai 4,1 triliun rupiah di Lombok Barat (www.regional.kompas.com/read/2018/09/10/07063251/lombok-barat-rugirp-41-triliun-akibat-gempa-pemda-akan-ngamen-ke-pusat/. Berdasar dari data Bank Indonesia, pertumbuhan ekonomi NTB pada triwulan ketiga 2018 mengalami kontraksi 4,56 
persen, yang berarti penurunan aktivitas perekonomian yang tajam. Secara mikro, 876 rumah warga Desa Guntur Macan rusak berat. Faktor mikro lainnya, warga yang terluka secara fisik tak bisa bekerja pada sementara waktu. Rusaknya berbagai kantor, pasar, maupun gedung bisnis menyebabkan berbagai transaksi terhenti dan para pekerja beralih profesi. Faktor keamanan juga menyebabkan mayoritas wisatawan pergi dari Lombok, sedang wisatawan yang akan berkuntung tak berani masuk.

Kondisi tersebut menyebabkan meningkatnya pengangguran, termasuk pemuda. Di Lombok Barat, terdapat 10.381 pengangguran pada tahun 2016 (NTB Dalam Angka, 2016). Jumlah saat ini diperkirakan melonjak dari angka tersebut. Pertambahan pengangguran di Desa Guntur Macan juga disebabkan pertambahan angka putus sekolah.

Pengangguran dan putus sekolah berpotensi menimbulkan dampak negatif dalam kehidupan sosial. Remaja putus sekolah berpotensi terpuruk dalam hubungan kerja yang merugikan dan eksploitatif (Suyanto, 2016). Sementara itu, Peneliti PSKK UGM, Triyastuti Setianingrum (2017) menyatakan bahwa putus sekolah dan kemiskinan saling berpengaruh. Putus sekolah menambah pengangguran, serta berpotensi meningkatkan kenakalan anak dan tindak kejahatan (www.student.cnnindonesia.com/edukasi/20170417145047-445-208082/ tingginya-angka-putus-sekolah-di-indonesia/).

Perlu upaya untuk menanggulangi dan mengantisipasi dampak negatif dari putus sekolah dan pengangguran. Pembentukan komunitas pemuda yang bergerak di bidang sosial dan ekonomi adalah alternatif solusi yang tepat. Membentuk komunitas sosial sama halnya dengan menumbuhkan modal sosial. Anasir modal sosial adalah; kelompok yang dibentuk untuk membangun jejaring sosial, kepercayaan yang dilembagakan untuk mengembangkan solidaritas sosial, tindakan kolektif untuk mengokohkan kerja sama, dan pemberdayaan untuk memperkuat posisi tawar kekuasaan (Usman, 2018). Dengan mengaktivasi komunitas, sama halnya dengan (1) mencipta kelompok yang dibentuk untuk membangun jejaring sosial, (2) melembagakan kepercayaan sekaligus mengembangkan solidaritas sosial, (3) wujud tindakan kolektif untuk mengokohkan kerja sama, serta (4) pemberdayaan untuk memperkuat posisi tawar kekuasaan.

Oleh karenanya, sebagai partisipasi dalam menangani permasalahan di Desa Guntur Macan di atas, perlu pembentukan komunitas pemuda kreatif Desa Guntur Macan guna meningkatkan kreativitas berusaha (khususnya dalam bidang ekonomi dan sosial). Komunitas ini juga sebagai wadah pemuda, pengangguran, dan remaja putus sekolah untuk aktif dalam kegiatan sosial dan ekonomi. Sekaligus mengantisipasi dampak negatif fenomena remaja putus sekolah dan pemuda pengangguran.

\section{METODE KEGIATAN}

Pembentukan komunitas tersebut diawali dengan pemetaan potensi pemuda melalui pendekatan kultural dan struktural. Perlu diselenggarakan FGD (focus group discussion) yang menyertakan pemuda Desa Guntur Macan sebagai peserta utama. FGD ini berfungsi memahamkan urgensi pembentukan komunitas pemuda kreatif, sekaligus rekayasa sosial menumbuhkan minoritas kreatif sebagai unsur perubahan. Program selanjutnya: Sarasehan dan Launching Komunitas, sebagai upaya menyamakan persepsi antara pemuda dan warga desa, serta pengokohan terbentuknya komunitas pemuda kreatif. Kegiatan ini menghasilkan 
terbentuknya komunitas pemuda kreatif (yang diberi nama KPK) Desa Guntur Macan, yang berimbas pada kegiatan-kegiatan positif lainnya: workshop Cara Murah d an Kreatif Mengolah Botol Bekas Menjadi Hiasan Berharga, dan pelatihan Cara Kreatif Membangun Jejaring Sosial Online Tanpa Keluar Rumah. Hingga saat ini, adanya KPK berimbas juga pada terbentuknya usaha bersama budidaya lebah Trigona dan usaha produksi hiasan dari bahan bekas. Selain itu, di internal pengurus KPK rajin sharing dan diskusi terutama via online melalui Whatsapp Group KPK Guntur Macan.

Metode kegiatan dalam pengabdian ini dapat digambarkan dalam bagan sebagai berikut:

Gambar 1. Kerangka metode kegiatan

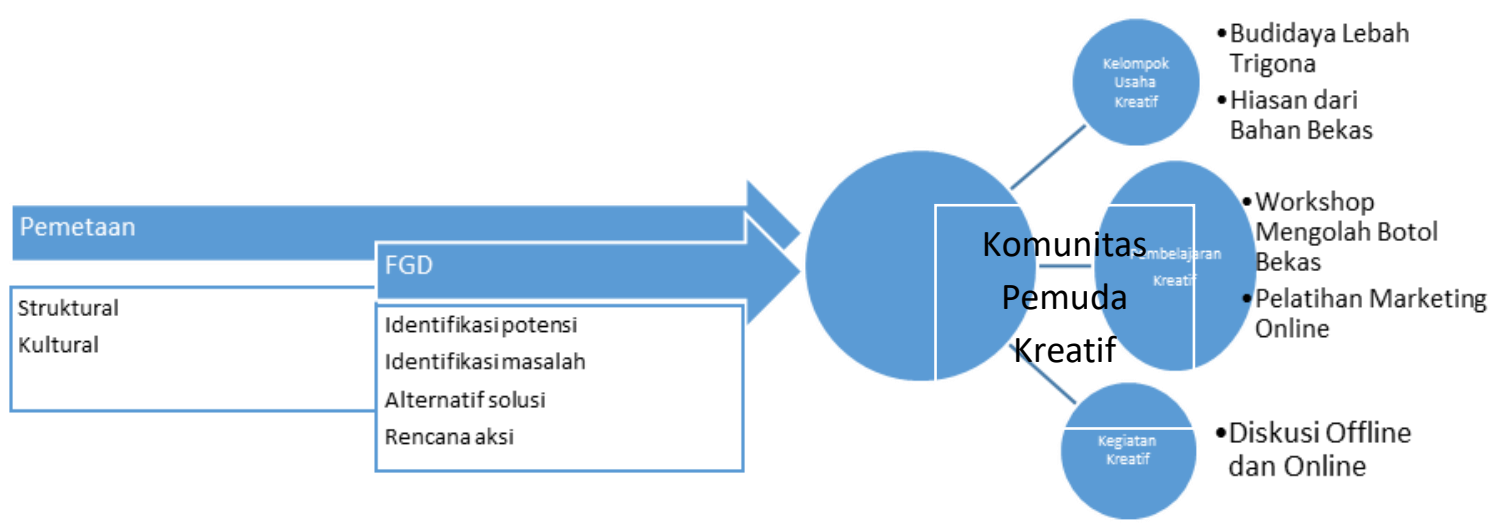

\section{HASIL DAN PEMBAHASAN}

Untuk mengidentifikasi masalah sekaligus potensi desa,khususnya yang berkaitan dengan sosial-ekonomi dan pemuda, dilakukan melalui dua pendekatan: struktural dan kultural. Dua pendekatan ini dilakukan secara kualitatif. Struktural melalui wawancara dengan perangkat desa, terutama Sekretaris Desa (Jamaah). Dari wawancara tatap muka, didapati bahwa terdapat banyak pengangguran dan remaja putus sekolah di desa ini. Selain itu, sudah terdapat individu-individu pemuda yang telah bergerak dalam bidang usaha, namun belum terkoneksi antar satu dan lainnya, sehingga belum saling menguatkan.

Sedang secara kultural, dilakukan wawancara dan diskusi pada individu pelaku usaha (Aprianto). Dari kegiatan ini, disimpulkan bahwa sudah terdapat kelompok usaha kreatif pemuda (produksi dan pemasaran kerajinan tangan: bros), namun belum terdapat komunitas usaha kreatif. Selain wawancara dan diskusi person to person, dilakukan juga FGD yang melibatkan pemuda pelaku usaha serta tokoh pemuda.

FGD yang dilakukan pada bulan Agustus 2019 lalu, diikuti oleh enam pemuda, bertempat di balai desa Guntur Macan. FGD ini diperlukan, guna menumbuhkan minoritas elit yang kreatif (Lauer), sarana bertukar informasi dan ide menumbuhkan kreativitas gagasan dan kerja, serta penumbuhan dan penguatan modal sosial. Dari FGD ini diketahui bahwa desa Guntur Macan memiliki potensi wisata alam, potensi wisata tani 
(perkebunan aren), perkebunan (gula aren, kolang-kaling), pertanian, peternakan (lebah trigona), kuliner, tata-boga, dan kerajinan. Selain memiliki potensi masalah terkait penumpukan sampah. FGD ini menghasilkan, disepakati dan dibentuknya komunitas pemuda kreatif yang dinamai KPK Guntur Macan, dan Aprianto menjadi koordinatornya. Peserta FGD ini juga menyepakati rencana aksi, yakni pelatihan dan workshop mengolah barang bekas (sampah) menjadi hiasan berharga serta marketing online.

Pada tanggal 1 September 2019, bertempat di Balai Desa Guntur Macan, diselenggarakan launching KPK dan dilanjutkan dengan pelatihan dan workshop. Acara ii diikuti 30 pemuda dari tujuh dusun di Guntur Macan. Acara ini menghadirkan Perangkat Desa Guntur Macan, nara sumber dari Prodi Sosiologi, serta professional pelaku usaha. Agar suatu lembaga bisa kuat, diperlukan legitimasi dari tokoh dan akademisi. Sosiolog berperan menjelaskan urgensi komunitas sebagai agen perubahan, sekaligus penguatan modal sosial berbasis trust dan friendship. Selanjutnya diselenggarakan workshop Cara Murah dan Kreatif Mengolah Botol Bekas Menjadi Hiasan Berharga, dan pelatihan Cara Kreatif Membangun Jejaring Sosial Online Tanpa Keluar Rumah. Kegiatan ini diberitakan oleh koran Suara NTB pada 3 September 2019 dengan judul Prodi Sosiologi Unram Bentuk Komunitas Pemuda Kreatif.

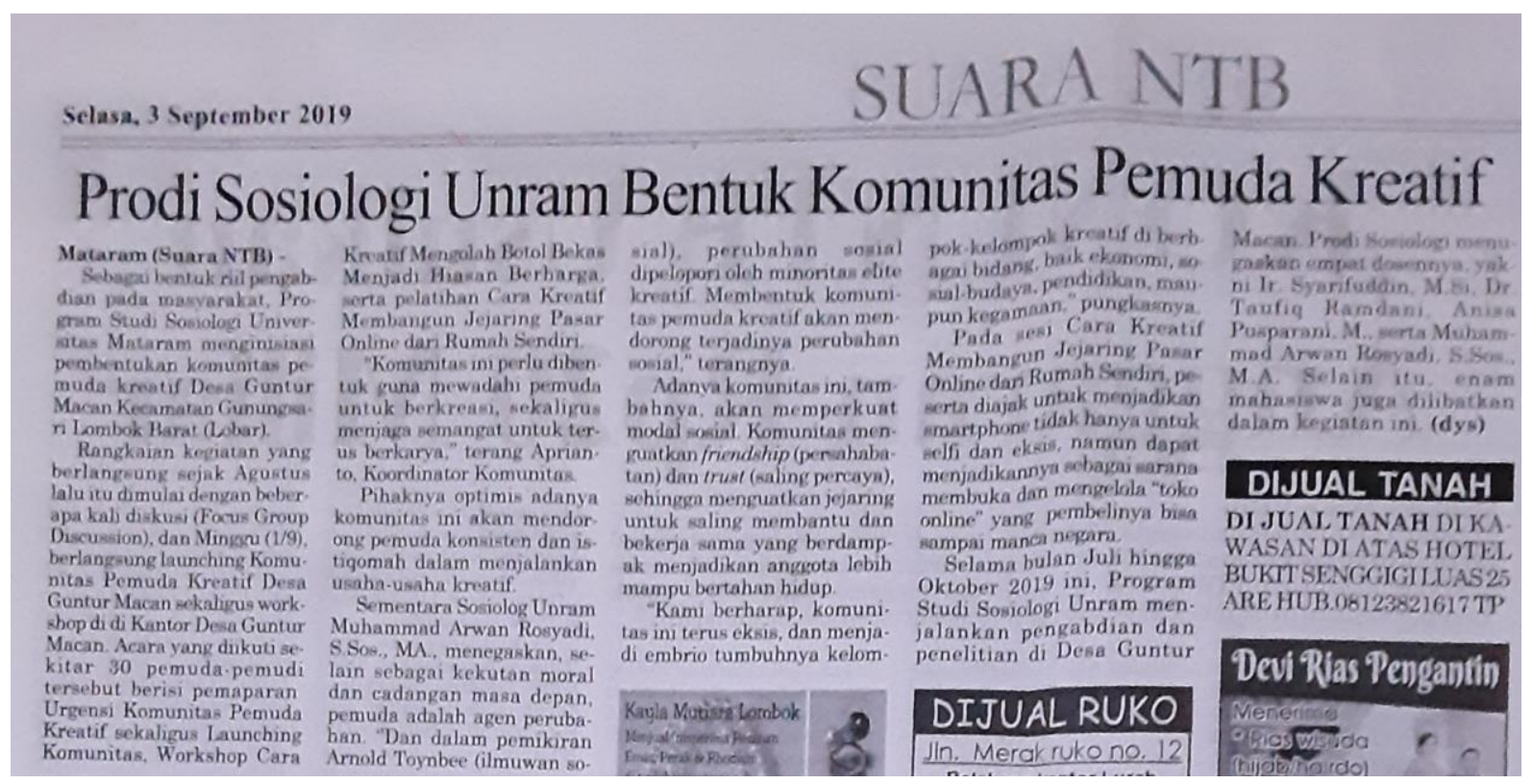

Gambar 2 Berita Pengabdian di Koran Suara NTB

Kegiatan lanjutan dari komunitas pemuda kreatif ini adalah ngobrol dan diskusi melalui Grup di aplikasi Whatsapp KPK Guntur Macan. Hingga akhir September ini, adanya KPK Guntur Macan ini juga mendorong tumbuhnya usaha bersama budidaya lebah Trigona serta produksi hiasan dari barang bekas. 


\section{KESIMPULAN DAN SARAN}

Dari pengabdian yang telah dilakukan ini, dapat disimpulkan sebagai berikut:

Kegiatan pokok dalam pengabdian ini dapat terlaksana, yakni; Pembentukan Komunitas Pemuda Kreatif (KPK) Desa Guntur Macan

Pembentukan KPK Desa Guntur Macan dilakukan melalui pendekatan kultural (para pemuda desa) dan struktural (pemerintah desa). Pendekatan kultural dilakukan dengan pendekatan personal (diskusi face-to-face) dan FGD (focus group discussions), sedang struktural dilakukan melalui wawancara sekretaris desa.

- Adanya KPK berimbas pada pelaksanaan workshop Cara Murah dan Kreatif Mengolah Botol Bekas Menjadi Hiasan Berharga, dan pelatihan Cara Kreatif Membangun Jejaring Sosial Online Tanpa Keluar Rumah.

Adanya KPK dan workshop tersebut juga menumbuhkan usaha baru Mengolah Botol Bekas Menjadi Hiasan Berharga serta Budidaya Lebah Trigona

\section{Saran}

Perlu kegiatan pengabdian lanjutan agar KPK tetap eksis dan berkembang, misalnya dengan pemberian pelatihan tentang community management, maupun manajemen bisnis dan keuangan usaha mikro.

\section{Ucapan Terima Kasih}

Penulis mengucapkan terima kasih kepada Lembaga Penelitian dan Pengabdian Kepada Masyarakat Universitas Mataram yang telah memberi dukungan berupa ijin dan fasilitasi penyediaan keuangan pada pengabdian ini.

\section{DAFTAR PUSTAKA}

BPS Provinsi NTB. PROVINSI NUSA TENGGARA BARAT DALAM ANGKA. 2016. BPS Provinsi NTB. Mataram.

Data Miskin Desa Guntur Macan www.desagunturmacan.com diakses tanggal 19 Februari 2019 Pukul 20.05 WITA

Lauer, Robert H. 1993. Perspektif tentang Perubahan Sosial. Jakarta: Rineka Cipta.

Lombok Barat Rugi 4,1 Triliun. www.regional.kompas.com diakses pada tanggal 19 Februari 2019 Pukul 20.00 WITA

Suyanto, Bagong. 2016. Masalah Sosial Anak. Jakarta: Purnamedia Group.

Tingginya Angka Putus Sekolah di Indonesia. www.student.cnnindonesia.com diakses 19 Februari 2019 Pukul 20.01 WITA.

Usman, Sunyoto. 2018. Modal Sosial. Yogyakarta: Pustaka Pelajar. 